\title{
Biografia: Prof. Dr. Walter Baptist Mors (1920-2008)
}

por Gilda Guimarães Leitão

Data de publicação na Web: 06 de Abril de 2011 Recebido em 01 de Abril de 2011 Aceito para publicação em 06 de Abril de 2011

Nascido em 23 de novembro de 1920 na cidade de São Paulo, o Professor Walter Baptist Mors formou-se em Química, em 1942, pela Faculdade de Filosofia Ciências e Letras da Universidade

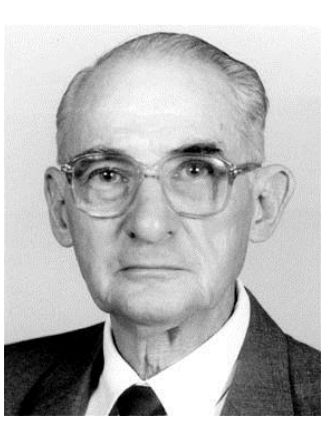
de São Paulo (USP). Em 1943, ingressou no Instituto Agronômico do Norte, do Ministério

Agricultura, em Belém, Pará, onde adquiriu o gosto pela Botânica Econômica que cultivou durante toda a vida. Em 1947 transferiu-se para o Instituto de Química Agrícola (I.Q.A.), no Rio de Janeiro, onde ingressou, com a finalidade de desenvolver pesquisas com plantas tóxicas para o gado na Seção de Química Vegetal. Ali foi onde consolidou sua afeição pela Química dos Produtos Naturais. Nessa época, também, nasceu o interesse de Walter Mors pelas relações entre química e sistemática botânica. Um fato importante na sua vida foi ter trabalhado como bolsista da Fundação Rockefeller, na Wayne State University, em Detroit, com Carl Djerassi, que seria, mais tarde, importante contribuidor e impulsionador da química de produtos naturais nos seus primórdios no Brasil. Ocorreu ainda no I.Q.A., o seu primeiro contato com propriedades biodinâmicas de produtos naturais, assunto que seria mais tarde aprofundado na Universidade. Em 1960 obteve o titulo de Doutor e tornou-se Livre-Docente pela UFRJ. Com a extinção do I.Q.A. em 1962, Walter B. Mors, junto com outros pesquisadores de renome, a convite do Prof. Paulo da Silva Lacaz, fundaram o Centro de Pesquisas de Produtos Naturais (CPPN, atual NPPN), situado na Faculdade de Farmácia da então Universidade do Brasil, no campus da Praia Vermelha. Em 1975, o CPPN foi transferido para o campus da llha do Fundão, onde, em 1976, oficializado pelo Conselho Universitário, passou a ser um órgão suplementar e ter status de núcleo, passando então a se chamar Núcleo de Pesquisas de Produtos Naturais - segundo o Reitor à época, Luiz Renato Caldas, não poderia existir um centro dentro de outro centro (no caso, o Centro de Ciências da Saúde, onde está localizado até hoje o NPPN). Walter Mors, sempre dedicado ao NPPN, ali deixou sua marca e um grande legado à química dos produtos naturais, tendo implantado linhas de pesquisa que até hoje são inspiradoras de pesquisas no NPPN. Em colaboração com muitos colegas e alunos foi produzida uma longa série de trabalhos sobre produtos naturais, destacando-se a identificação do 14,15-epóxigeranilgeraniol, a substância ativa do óleo dos frutos da Sucupirabranca (Pterodon pubescens), que impede a penetração das cercárias do Schistosoma na pele do hospedeiro definitivo (publicado na revista Science, em 1967); do princípio hipoglicemiante da planta anti-diabética Pedra-umecaá (Myrcia uniflora); e numerosas pesquisas sobre flavonóides, muitos deles inéditos, sendo alguns apontados como indicadores evolutivos no gênero onde ocorrem. Destacam-se, nesse legado, os estudos com plantas usadas em doenças endêmicas, hoje chamadas de "doenças negligenciadas" e os estudos sobre plantas usadas contra picadas de cobra, conhecidas como "antiofídicas". Este tema, que foi carro-chefe das pesquisas no NPPN durante muito tempo e até hoje inspira seus pesquisadores, seja na área da fitoquímica seja na área da síntese orgânica, levou Walter Mors a estudar o princípio ativo da Erva-botão (Eclipta prostata). Essa planta foi por ele escolhida depois de ver seu sucesso como antiofídica entre índios e caboclos da Amazônia. Em 1994, Walter Mors (NPPN) isolou o produto natural wedelolactona da Ervabotão, e com Paulo Melo, do Departamento de Farmacologia Básica e Clínica da UFRJ, demonstram sua ação in vitro.

Walter B. Mors foi um pioneiro ao perceber, ainda nos anos 50, a importância de uma visão multidisciplinar da pesquisa com plantas, permeando aspectos da Botânica, Química e Farmacologia, unindo químicos, farmacêuticos, botânicos e farmacólogos. Com Carlos Toledo Rizzini escreveu o livro "Botânica Econômica 
Brasileira" (com edições em de Desenvolvimento Científico e português, inglês e alemão) e Tecnológico-CNPq/Financiadora de também com Carlos Toledo Rizzini e Nuno Álvares Pereira, é co-autor do livro "Medicinal Plants of Brazil". Integrou inúmeros Conselhos e Grupos de Trabalho, entre eles o grupo de trabalho sobre Plantas Tropicais Subaproveitadas de Valor Econômico Promissor, da National Academy of Sciences dos Estados Unidos. Coordenou o grupo de trabalho internacional para elaboração do Programa Interciência de Recursos Biológicos e, ainda, o Grupo Assessor do Programa "Cultivos Pioneiros" do Conselho Nacional
Estudos e Projetos - FINEP.

Membro da Academia Brasileira de Ciências, desde 1957,foi seu Secretário-Geral por dois períodos. Presidiu a Associação Brasileira de Química - $A B Q$ e a Federación Latino-Americana de Asociaciones Químicas. Seu mérito científico foi reconhecido através da condecoração com a Grã-Cruz da Ordem Nacional do Mérito Científico, em Setembro de 1994, e da medalha Simão Mathias, outorgada, em 2001, pela Sociedade Brasileira de Química.
Aposentado desde 1991, Walter B. Mors continuou colaborando com o NPPN durante os muitos anos que antecederam o seu falecimento. Por seus feitos na química de produtos naturais no Brasil e na criação de grupos de pesquisa na área, Walter B. Mors ocupa, sem dúvida, um lugar de destaque na história da ciência brasileira.

Núcleo de Pesquisas de Produtos Naturais, Universidade Federal do Rio de Janeiro, Avenida Carlos Chagas Filho, 373, Centro de Ciências da Saúde, Bloco H, Ilha do Fundão, Rio de Janeiro, RJ, 21.941-590, Brasil.

Mggleitao@nppn.ufri.br 